\title{
O dossiê na perspectiva de lideranças Katxuyana e Kahyana hoje: ainda existimos, não desistimos, somos muitos yanas
}

\author{
Angela Kahyana* \\ Mauro Mïkaho Tiriyó Katxuyana * \\ Juventino Pesirima Junior* * *
}

\begin{abstract}
KAHYANA, A.; KATXUYANA, M.M.T.; PESIRIMA JUNIOR, J. O dossiê na perspectiva de lideranças Katxuyana e Kahyana hoje: ainda existimos, não desistimos, somos muitos yanas. R. Museu Arq. Etn. 37: 24-27, 2021.
\end{abstract}

Resumo: Neste capítulo, Angela Kahyana, Mauro Mikaho Tiriyó Katxuyana e Juventino Pesirima Junior, lideranças indígenas contemporâneas cujos antepassados ocuparam a região do rio Cachorro e Trombetas, na mesma época em que os textos em alemão foram produzidos, relatam suas perspectivas acerca deste Dossiê, apontando a contribuição desses registros históricos sobre seus antepassados, sua forma de viver, seus rituais, a diversidade de sua cultura material e, principalmente, a ocupação territorial. As lideranças percebem que os textos de Kruse, Polykrates e Detering, que compõem este volume, têm a marca de seu tempo, sobretudo porque apontavam uma preocupação em comum: a de que esses povos desapareceriam. Contradizendo tais previsões ao ultrapassarem inúmeras adversidades, esses povos (ou yanas), suas famílias e parentes persistiram em sua resistência e luta pela defesa de seus direitos territoriais e reconhecimento de suas culturas.

Palavras-chaves: Yana; Katxuyana; Kahyana; rio Cachorro; Rio Trombetas.

\section{Depoimento de Angela Kahyana}

" $\mathrm{Q}$ om, quero falar primeiro sobre a importância da junção de todos esses documentos, de todos esses registros sobre a nossa essência, que fazem parte não só da história de um povo, mas do significado do que nós somos enquanto yana.

Quando vejo as diferentes formas de transmissão ou de interpretação e de registro dessas vivências, isso nos remete a um passado

* Membro da diretoria da Coordenação das Organizações Indígenas da Amazônia Brasileira (Coiab). <ymeriki.kaxuyana@gmail.com>

** Professor indígena, cacique da aldeia Impotpirï.

*** Membro da Associação Indígena Katxuyana, Tunayana e Kahyana (Aikatuk). recente que, inclusive, foi pouco estudado e pouco registrado, ou mesmo pouco mencionado, e que nos remete às histórias dessa diversidade de yanas, aos significados dos rituais e da ocupação territorial. Essas histórias nos remetem muito a isso: quem somos nós no ambiente, dentro do território, com toda nossa diversidade e cosmologia. Este é um material extremamente importante, não só para a recuperação da memória, mas daquilo que vivemos no tempo, num passado muito recente. Lendo tudo isso, eu tenho muito a impressão de que estou diante de uma história que meu avô contou de quando ele vivenciou tudo isso. Mas também esses textos nos reconectam com uma geração que não viveu essa história, nos reconectam com o sentido e 
o compromisso de permanecermos cuidando e transformando todo esse conhecimento de nossos avós, nossos bisavós. Para mim, também é como trazer de volta aquilo que por um tempo esteve escondido: quem somos enquanto Kahyana, enquanto Katxuyana, enquanto Yaskuryana. A gente sempre teve essa memória, mas nunca teve uma memória escrita sobre isso, que a gente pudesse externalizar de forma que outras pessoas pudessem ter acesso e conhecimento sobre a nossa vida, sobre quem de fato nós somos como moradores pertencentes a esses rios tão importantes na nossa região, que são o Kahu [Trombetas] e o Katxuru [Cachorro].

Então, essa história remete também à própria existência desses dois grandes rios, e o que eu diria é que ela é uma transmissão da nossa essência, da nossa história, da nossa existência enquanto povos dessa região. Isso nos reconecta com quem fomos e com quem continuamos sendo enquanto yanas, e esta publicação é a oportunidade de que outras pessoas possam também conhecer, não só a nossa história, mas o que é esse sentimento de pertencimento a esses yanas todos (Kahyana, Katxuyana, Yaskuriyana etc.).

É nesse sentido que eu socializo sobre a importância desta publicação, de a gente também poder olhar, ter esse sentimento de que tudo que está escrito aí nesses documentos, nos envolve, nos diz respeito. Quando eu leio, passa um filme de quanto meu avô, minha avó, viveram isso tudo; é uma história não muito distante, é uma história das pessoas reais, inclusive as pessoas que são citadas nesses documentos, muitos de nós chegamos a conhecer e conviver. Então, é muito importante nesse sentido, e agora é isso, cada leitura, cada descoberta de registro nos transforma, nos reconecta e nos fortalece também enquanto afirmação e reafirmação de nós mesmos, enquanto pertencentes a esses diversos yanas.

Eu acho que não faz parte totalmente dos textos deste Dossiê o que quero transmitir, mas também é um sentimento que eu sempre tive de que muitas obras, muitos registros foram feitos na perspectiva de que esses povos iriam desaparecer, de que eram os últimos contatos, que a nossa expedição é para chegar aqui e registrar os últimos dos últimos; e eu acho fantástico que essas obras, esses registros não eram os últimos, como pensava Frikel, por exemplo ao escrever sobre 'os últimos Kahyana'. E a gente, hoje, tem uma oportunidade, em 2021, de falar e mostrar isso. Nós estamos com essa oportunidade de fazer essa releitura, e é releitura mesmo, porque quando a gente lê agora, a gente lê com outro olhar, com outra perspectiva sobre o que de fato foi registrado, e é muito importante esse nosso posicionamento enquanto descendentes dessas pessoas que foram estudadas, que foram vistas. Também é impressionante eu, enquanto Kahyana, falar aqui e me posicionar e de certa forma me sentir representada, dando resposta a esses registros; eu me sinto com essa abertura, com essa voz, uma oportunidade de ter a minha voz sendo escutada; não éramos os últimos, estamos aqui, resistimos, permanecemos apesar de todas as violências que nós passamos e tentativas de que, realmente, tivéssemos sido os últimos.

Eu fico imaginando que, nesse espaço da nossa resposta, nos caiba também fazer uma linha do tempo - do tempo que esses documentos registram, do tempo em que houve um processo de transição totalmente adverso para nós, do tempo que a gente viveu um impacto muito brusco, mas também do tempo de hoje, de poder dar esse retorno e dizer: 'passamos por isso e passamos por outros processos, mas estamos aqui!'.

Por último, eu fico muito impressionada com esses registros, essas anotações, essas percepções. Muitas delas são valiosas para nós, uma leitura dos acontecimentos, principalmente dos significados da definição do pertencimento. Elas são muito bem registradas - claro que as escritas interpretam, algumas são bastante equivocadas, isso é óbvio porque partem da leitura de quem tá chegando, de quem tá observando, e não de quem vive, e não de quem vivencia essa vida. Mas é importante o registro para também fortalecer o que falei desse pertencimento, desse significado de fazer parte de um yana, parte da história. Por que não é Katxuyana? Como assim é Kahyana? Ou é Ingarinyana? Por que temos essa conexão entre diversos yanas e por que que há essa diversidade de yanas? Eu acho que essa história e esses escritos têm muita importância também para as pessoas que hoje estão trabalhando, pesquisando e nos ajudando a entender isso. Mas considero que o 
mais importante é essa reafirmação do significado, a essência de se pertencer a um yana para os jovens de hoje, que não tiveram essa oportunidade de conviver, de escutar e de sentir essa emoção de você de fato passar por uma transição do conhecimento dos mais velhos para um processo mais recente.

Outro pensamento que me veio à mente lendo esses textos é sobre a importância do papel da mulher. Eu sempre reafirmei que a tomada de decisões dentro das aldeias foi algo muito vinculado às mulheres, e não a essa figura masculina que muitas pessoas criaram, que o colonialismo criou, essa imagem que o cacique homem é o tomador de decisão. Mas lendo esses textos, eu fiquei super feliz de ver alguém afirmando aquilo que sempre defendi: que quando se fala da roça, os homens fazem a roça, fazem todo o processo, cabendo às mulheres fazerem a plantação. Mas se os homens quiserem ser cavalheiros e fazer todo o processo, eles fazem, e sobra muito pouco para o que as mulheres vão precisar fazer, ou seja, as mulheres não vão fazer quase nada na roça e é exatamente isso que sempre reafirmei: há muito preconceito criado em relação ao papel das mulheres, de que os homens que comandam, que as mulheres são as que mais trabalham, e nunca foi assim. Essa leitura é muito de fora e ainda bem que isso está escrito aqui.

Num dos textos se fala exatamente isso.

Também fala que as mulheres estão lá conversando nos espaços, sempre respeitando o fato de que os homens têm mais regras para cumprir do que elas, e é uma leitura. Claro que, nesse contexto, quase não se dá ênfase ao papel dessas mulheres, mas é uma coisa para a gente estudar com carinho e com um olhar muito profundo sobre o papel das mulheres yana nesse processo: que todos os registros, todas as falas são muito ligadas aos homens, à figura dos homens. Para mim, isso é porque os homens que sempre foram procurados pelos pesquisadores Karaiwa (não indígenas), em sua maioria homens, que automaticamente procuravam os homens para conversar e para registrar. Então há muito registro e há muita percepção de homem para homem, e o escutar do homem. E a mulher, ela, na própria pesquisa ela é invisibilizada, mas quando você vai pesquisar a fundo o papel da mulher, a importância da tomada de decisões, inclusive nos rituais, você vai ver que as mulheres têm muito mais poder que os homens. E eu acho que era uma questão de vocês, pesquisadoras mulheres, um dia abordarem isso, algo que eu sempre digo e reafirmo: que a tomada de decisão principal nos processos das aldeias é das mulheres, não dos homens”.

\section{Depoimento de Mauro Mïkaho Tiriyó Katxuyana}

"Aqui é o Mauro Mikaho falando sobre um pouco da história do nosso povo Katxuyana. Eu quero agradecer muito o trabalho de vocês, que sempre trabalharam com a gente com o maior prazer. Primeiramente eu queria agradecer que vocês sempre estão continuando a trabalhar com a gente.

Então, eu gostaria de falar um pouco sobre a revista com os textos que foram escritos muitos anos atrás, para mim é muito importante saber que existe mesmo esse povo, porque com certeza os antigos antropólogos que passaram por aqui muitos anos atrás visitando o povo Katxuyana, com certeza eles sabiam; então, eles deixaram essa mensagem para que hoje em dia a nova geração possa saber que sempre existiu e que continua a existir esse povo. Então, para mim, é muito significante. Essa revista com certeza vai trazer o valor da história, do povo Katxuyana, para que todos conheçam e para que todos saibam que esse povo sempre existiu nessa região. Então, para mim, é muito importante esses textos antigos traduzidos para a linguagem portuguesa, para que o povo aqui no Brasil saiba também, e entenda, e estude sobre esse povo. Para considerar que estamos aqui habitando essa área antiga do povo Katxuyana, porque queremos recuperar e guardar essa história na memória. A gente quer deixar para as futuras gerações que virão essa história escrita. Eu sou geração do Waratanã Katxuyana Ingarï, com certeza é o pai do meu pai, meu tataravô, com certeza eles são de Ingarï. Ingarï se misturou com Katxuyana, Katxuyana se misturou com Tiriyó, então nós queremos apenas valorizar a nossa história. Meu muito obrigado, eu sou Mauro Mïkaho Tiriyó Katxuyana, e faço parte das lideranças aqui do rio Cachorro. Agradeço muito pelo trabalho que vocês estão fazendo para nós”. 


\section{Depoimento de Juventino Pesirima Junior}

"Sou Juventino, sou do povo Katxuyana, filho do Juventino Matxuwaya, então, quero agradecer ao [Instituto de Pesquisa e Formação Indígena] Iepé na pessoa da Denise, quero agradecer à Universidade Federal Fluminense (UFF), na pessoa da professora Adriana, pela publicação dos trabalhos dos pesquisadores das décadas de 1930 a 1950. Para nós, é importante que seja divulgada a nossa existência, pois muitos documentos não constam informações sobre nós, mas com essa revista, vai constar a nossa existência e vamos poder dizer ao povo brasileiro que nós sempre existimos e somos do território do Cachorro e Trombetas, de onde nós fomos por algum tempo afastados. Essa publicação vai trazer conhecimento ao fato da nossa existência e resistência, vai ajudar a valorizar o nosso povo e fortalecer a nossa luta.

Nós, como liderança, sempre cobramos das pessoas, dos pesquisadores, o retorno dos trabalhos. Portanto, quando encontramos com a professora Adriana pela primeira vez na aldeia Santidade, pedimos na época para ela procurar histórias do povo Katxuyana, histórias e artesanatos que foram levados embora no passado. E ela fez esse trabalho, ela foi para o exterior e colheu fotos, informações e revistas, que neste Dossiê agora estão publicadas. Isso vai nos fortalecer, pois muitos não consideram nós como povos da região, e vai trazer muitas histórias, muitos conhecimentos, não só para nós indígenas, mas aos que terão acesso a essas publicações, porque vamos ser melhor conhecidos. E espero que o povo que não nos conhece passe a nos conhecer, conhecer a nossa história, a nossa existência e resistência. Muitos jovens, nós mesmos, a gente tinha pouco conhecimento dessas histórias que estavam guardadas em língua alemã, escondidas, mas que bom, que bonito de ver tudo isso sendo publicado na Língua Portuguesa. Somos vários povos, muitas misturas, e esta publicação traz conhecimento para os jovens Katxuyana e Kahyana que não sabem, ainda não conhecem muita coisa. Por isso a gente agradece e apoia esta publicação, que está sendo realizada em parceria com Iepé, a Universidade Federal Fluminense e o Museu de Arqueologia e Etnologia da Universidade de São Paulo”.

KAHYANA, A.; KATXUYANA, M.M.T.; PESIRIMA JUNIOR, J. The Dossier from the perspective of Katxuyana and Kahyana leaders today: we still exist, we did not give up, we are many yanas. R. Museu Arq. Etn. 37: 24-27, 2021.

Abstract: This chapter reports the perspectives of Angela Kahyana, Mauro Mikaho Tiriyó Katxuyana, and Juventino Pesirima Junior - contemporary indigenous leaders whose ancestors occupied the region of the Cachorro and Trombetas rivers, concurrently with the production of the German texts - on this Dossier. The leaders discuss the contribution of these historical records about their ancestors, their way of living, their rituals, the diversity of their material culture, and, mainly, the territorial occupation. They also realize that the texts produced by Kruse, Polykrates, and Detering, which make up this Dossier, carry the mark of their time, especially for addressing a common concern: that these people would disappear. After overcoming countless adversities, these peoples (or yanas), their families and relatives contradict these predictions, resisting and struggling to defend their territorial rights and to promote the recognition of their cultures.

Keywords: Yana; Katxuyana; Kahyana; Cachorro river; Trombetas river. 